Pacific Journal of Mathematics

ON THE SPECTRAL RADIUS FORMULA IN BANACH 


\title{
ON THE SPECTRAL RADIUS FORMULA IN BANACH ALGEBRAS
}

\author{
JAN-ERIK BJÖRK
}

\begin{abstract}
$B$ will always denote a commutative semi-simple Banach algebra with a unit element. If $f \in B$ then $r(f)$ denotes its spectral radius. A sequence $F=\left(f_{j}\right)_{1}^{\infty}$ is called a spectral null sequence if $\left\|f_{j}\right\| \leqq 1$ for each $j$, while $\lim _{j \rightarrow \infty} r\left(f_{j}\right)=0$. If $F=\left(f_{j}\right)$ is a spectral null sequence we put $r_{N}(F)=$ $\lim \sup _{j \rightarrow \infty}\left\|f_{j}^{N}\right\|^{1 / N}$ for each $N \geqq 1$. Finally we define the complex number $r_{N}(B)=\sup \left\{r_{N}(F): F\right.$ is a spectral null sequence in $B\}$. In general $r_{N}(B)=1$ for all $N \geqq 1$ and the aim of this paper is to study the case when $r_{N}(B)<1$ for some $N$.
\end{abstract}

We say that $B$ satisfies a bounded inverse formula if there exists some $0<\varepsilon<1$ and a constant $K_{0}$ such that for all $f$ in $B$ satisfying $\|f\| \leqq 1$ and $r(f) \leqq \varepsilon$, it follows that $\left\|(e-f)^{-1}\right\| \leqq K_{0}$. In Theorem 3.1. we prove that $B$ satisfies a bounded inverse formula if and only if $r_{N}(B)<1$ for some $N$.

In $\S 1$ we give a criterion which implies that $B$ is a sup-norm algebra. In $\S 2$ we introduce the so called infinite product of $B$ which will enable us to study spectral null sequences in $\S 3$.

1. Sup-norm algebras. Recall that $B$ is a sup-norm algebra if there exists a constant $K$ such that $\|f\| \leqq K r(f)$ for all $f$ in $B$. Clearly this happens if and only if $r_{1}(B)=0$. Next we give an example where $r_{1}(B)=1$ while $r_{2}(B)=0$.

Let $B=C^{1}[0,1]$ be the algebra of all continuously differentiable functions on the closed unit interval. If $f \in B$ we put $\|f\|=$ $\sup \left\{|f(x)|+\left|f^{\prime}(y)\right|: 0 \leqq x, y \leqq 1\right\}$. The maximal ideal space $M_{B}$ can be identified with $[0,1]$, so the spectral radius formula shows that $r(f)=\sup \{|f(x)|: 0 \leqq x \leqq 1\}$. From this we easily deduce that $r_{2}(B)=$ 0 . In fact we also notice that $\left\|f^{n}\right\| \leqq n\|f\|(r(f))^{n-1}$ holds for all $n \geqq 2$. We will now prove that this estimate is sharp.

THEOREM 1.1. Let the norm in $B$ satisfy $\left\|f^{n}\right\| \leqq q n\|f\| r(f)^{n-1}$ for some $q<1$ and some $n \geqq 2$. Then $B$ is a sup-norm algebra and there is a constant $K(n, q)$ such that $\|f\| \leqq K(n, q) r(f)$ for all $f \in B$.

Lemma 1.2. Let $n \geqq 3$ and suppose that $\left\|f^{n}\right\| \leqq K\|f\| r(f)^{n-1}$ for all $f$ in $B$ and some constant $K$. Then there is a constant $K(n)$ such that $\left\|f^{2}\right\| \leqq K(n) K\|f\| r(f)$. 
Proof. Notice that all the inequalities above are homogeneous. Hence it is sufficient to consider the case when $\|f\|=1$. If now $r(f)=\varepsilon$, then we must prove that $\left\|f^{2}\right\|<K(n) K \varepsilon$ for some $K(n)$.

Under the hypothesis, we note that

$$
\left\|(k \varepsilon+f)^{n}\right\| \leqq K\|k \varepsilon+f\|(\varepsilon+k \varepsilon)^{n-1} \leqq K \varepsilon^{n-1}(1+n)^{n}
$$

for all $0 \leqq k \leqq n$.

Now consider the inhomogeneous system of equations

$$
\sum_{j=0}^{n}\left(\begin{array}{c}
n \\
j
\end{array}\right)(k \varepsilon)^{n-j} f^{j}=(k \varepsilon+f)^{n}, \quad 0 \leqq k \leqq n,
$$

which we wish to solve for the $f^{j}$. The determinant of the system is $\varepsilon \varepsilon^{2} \cdots \varepsilon^{n} K_{0}(n)$, and the determinants of the minors can be expressed similarly. Using Cramer's rule to solve this system for $f^{2}$, we obtain the estimate $\left\|f^{2}\right\| \leqq K(n) K \varepsilon$, as required.

Proof of Theorem 1.1. Firstly we choose $\varepsilon>0$ so small that $1-\varepsilon^{n}>2 n \varepsilon^{n}+q$. Next we introduce the power series $\phi(z)=\varepsilon+$ $a_{1} z+a_{2} z^{2}+\cdots$, which satisfies $(\phi(z))^{n}=\varepsilon^{n}+z$ for all $|z|<\varepsilon^{n}$. Notice that $n a_{1} \varepsilon^{n-1}=1$ holds. If $0<x<\varepsilon^{n}$ we put

$$
A_{v}(x)=x^{v}\left(\left|a_{v n}\right|+\cdots+\left|a_{v n+n-1}\right|\right) .
$$

Then it is clear that the sum $U(x)=A_{1}(x)+A_{2}(x)+\cdots$ is finite, while $\lim U(x)=0$ as $x \rightarrow 0$.

Note that from Lemma 1.2. there is a constant $K(n)$ such that $\left\|f^{k}\right\| \leqq K(n) r(f)$ for all $2 \leqq k \leqq n-1$ and all $f$ in $B$ satisfying $\|f\| \leqq 1$. It follows that there is a constant $K(n, \varepsilon)$ such that $\left\|a_{2} f^{2}+\cdots+a_{n-1} f^{n-1}\right\| \leqq K(n, \varepsilon) r(f)$ for all $f$ satisfying $\|f\| \leqq 1$.

Now we choose $\delta>0$ so small that $n \delta^{n-1}<\varepsilon^{n}$ and $U\left(n \delta^{n-1}\right)+$ $K(n, \varepsilon) \delta<\varepsilon$ holds.

Suppose now that $B$ is not a sup-norm algebra. Then we can choose $f$ in $B$ such that $\|f\|=1$ while $r(f)<\delta$. The assumption shows that $\left\|f^{n}\right\| \leqq q n \delta^{n-1} \leqq n \delta^{n-1} \leqq \varepsilon^{n}$. Hence $\left\|f^{v n+k}\right\| \leqq\left\|f^{n}\right\|^{v}\left\|f^{k}\right\| \leqq$ $\left(n \delta^{n-1}\right)^{v} \rightarrow$ for all $v \geqq 1$ and all $k=0 \cdots(n-1)$. It follows that we can define the element $g=\phi(f)=\varepsilon+a_{1} f+a_{2} f^{2}+\cdots$ in $B$.

We get $\|g\| \leqq \varepsilon+\left|a_{1}\right|+\left\|a_{2} f^{2}+\cdots+a_{n-1} f^{n-1}\right\|+U\left(n \delta^{n-1}\right) \leqq$ $2 \varepsilon+\left|a_{1}\right|$. We also have $r(g) \leqq\left(r\left(\varepsilon^{n}+f\right)\right)^{1 / n} \leqq\left(\varepsilon^{n}+\delta\right)^{1 / n}$.

It follows that $1-\varepsilon^{n} \leqq\left\|\varepsilon^{n}+f\right\|=\left\|g^{n}\right\| \leqq q n\|g\| r(g)^{n-1} \leqq$ $q n\left(2 \varepsilon+\left(n \varepsilon^{n-1}\right)^{-1}\right)\left(\varepsilon^{n}+\delta\right)^{1-1 / n}=Z(\delta)$.

Clearly $Z(\delta)$ tends to $2 q n \varepsilon^{n}+q$ as $\delta \rightarrow 0$. The original choice of $\varepsilon$ shows that $1-\varepsilon^{n} \leqq Z(\delta)$ cannot hold for sufficiently small values of $\delta$. This proves that $B$ must be a sup-norm algebra and the proof gives a lower bound for $\delta$, once we have fixed $\varepsilon$. 
2. The infinite product of a Banach algebra. Firstly we introduce the infinite product.

Definition 2.1. Put $B_{\infty}=\left\{\left(f_{j}\right)_{1}^{\infty}:\left(f_{j}\right)\right.$ is a sequence in $B$ such that $\sup _{j}\left\|f_{j}\right\|<\infty$ while $\lim _{j \rightarrow \infty} r\left(w e-f_{j}\right)=0$ for some $\left.w \in C^{1}\right\}$.

Clearly $B_{\infty}$ is a Banach algebra if to each $F=\left(f_{j}\right)$ we define $\|F\|=\sup _{j}\left\|f_{j}\right\|$. If $F=\left(f_{j}\right)$ and if $N \geqq 1$, then we put $\pi_{N}(F)=$ $\left(g_{j}\right)$, where $g_{j}=0$ for $j \leqq N$ and $g_{j}=f_{j}$ for $j>N$.

A complex-valued homomorphism $H$ on $B_{\infty}$ is free if $H(F)=$ $H\left(\pi_{N}(F)\right)$ for all $N \geqq 1$ and each $F \in B_{\infty}$. The part at infinity in $M_{B_{\infty}}$ consists of the points determined by free homomorphisms. We denote this set by $M_{\infty}$.

To each $N \geqq 1$ we have an idempotent $e_{N}$ in $B_{\infty}$, whose $N$ th component is $e$ while all the other components are zero. The set $\Delta_{N}=\left\{x \in M_{B_{\infty}}: \hat{e}_{N}(x)=1\right\}$ is a clopen (closed and open) subset of $M_{B_{\infty}}$. We can identify $\Delta_{N}$ with $M_{B}$. For if $x \in M_{B}$ we get a point $T_{N}(x)$ in $\Delta_{N}$ satisfying $\hat{F}\left(T_{N}(x)\right)=\hat{f}_{N}(x)$ for all $F=\left(f_{j}\right)$. It is easily seen that $T_{N}$ is a homeomorphism from $M_{B}$ onto $\Delta_{N}$.

If we put $\Delta=\bigcup \Delta_{N}: N \geqq 1$, then it is easily seen that $\Delta=$ $M_{B_{\infty}} \backslash M_{\infty}$. Here $\Delta$ is open and hence $M_{\infty}$ is closed. The set $M_{\infty}$ contains a distinguished point $m_{\infty}$, determined by the complex-valued homomorphism which sends $F=\left(f_{j}\right)$ into the complex number $w$ satisfying $\lim _{j \rightarrow \infty} r\left(w e-f_{j}\right)=0$.

With the notations above the following result is evident.

Lemma 2.2. Let $V$ be an open neighborhood of $m_{\infty}$ in $M_{B_{\infty}}$. Then there is an integer $N$ such that $\Delta_{j} \subset V$ for all $j>N$.

LEMMA 2.3. Let $b \Delta$ be the topological boundary of $\Delta$ in $M_{B_{\infty}}$. Then $b \Delta=\left\{m_{\infty}\right\}$.

Proof. Lemma 2.2. means that the clopen sets $\Delta_{N}$ converge to $\left\{m_{\infty}\right\}$. Then it is a trivial topslogical fact that $m_{\infty}$ is the only boundary point of $\Delta$.

The result below was motivated by Theorem 2 in [2].

Theorem 2.4. The set $M_{\infty}$ is a closed and connected subset of $M_{B_{\infty}}$.

Proof. We already know that $M_{\infty}$ is closed. Suppose next that $S$ and $T$ are disjoint closed subsets whose union is $M_{\infty}$, such that $m_{\infty} \in S$. Then Lemma 2.3. implies that $S \cup \Delta$ is clopen in $M_{B_{\infty}}$. By Shilov's idempotent Theorem there is $E \in B_{\infty}$ such that $\hat{E}=0$ on $S \cup \Delta$ while $\hat{E}=1$ on $T$. In particular $\hat{E}=0$ on each $\Delta_{j}$, which 
implies that the $j$ th component is zero. Since this holds for all $j$ we conclude that $E=0$, and $T$ is empty. Hence $M_{\infty}$ is connected.

The next result gives a useful characterization of $M_{\infty}$. This result is due to the referee.

THEOREM 2.5. Let $I$ be the closed ideal of all $F$ in $B_{\infty}$ for which $\lim \left\|\pi_{N}(F)\right\|=0$ as $N \rightarrow \infty$. Then $M_{\infty}$ is the maximal ideal space of $B_{\infty} / I$.

Proof. A point $m$ in $M_{B_{\infty}}$ induces a complex-valued homomorphism on $B_{\infty} / I$ if and only if $\hat{F}(m)=0$ for all $F \in I$. Clearly each idempotent $e_{N}$ belongs to $I$. This proves that if $m$ annihilates $I$, then $m$ must belong to $M_{\infty}$. Conversely, if $m \in M_{\infty}$ then $\hat{F}(m)=$ $\pi_{N}(F)^{\wedge}(m)$ for all $N \geqq 1$. Hence $|\hat{F}(m)| \leqq \lim _{N \rightarrow \infty}\left\|\pi_{N}(F)\right\|=0$ follows if $F \in I$. This proves that every point in $M_{\infty}$ annihilates $I$.

If $F=\left(f_{j}\right)$ is in $B_{\infty}$ we put $r_{N}(F)=\lim \sup _{j \rightarrow \infty}\left\|f_{j}^{N}\right\|^{1 / N}$ for each $N \geqq 1$. Let us also put $|F|_{\infty}=\sup \left\{|\hat{F}(m)|: m \in M_{\infty}\right\}$. With these notations the following result is a direct consequence of Theorem 2.5.

Proposition 2.6. If $F \in B_{\infty}$, then $|F|_{\infty}=\lim _{N \rightarrow \infty} r_{N}(F)$.

\section{Spectral null sequences.}

THEOREM 3.1. The following conditions on $B$ are equivalent:

(a) $r_{N}(B)<1$ for some $N \geqq 1$.

(b) $B$ satisfies a bounded inverse formula.

(c) There is a constant $K_{q}$ such that if $f \in B$ satisfies $\|f\| \leqq 1$ and $r(f)=q<1$, then $\left\|(e-f)^{-1}\right\| \leqq K_{q}(1-q)^{-1}$.

Proof. Since $(c) \rightarrow(b)$ we only prove that $(a) \rightarrow(b)$ and $(b) \rightarrow(a)$. Firstly we assume that $r_{N}(B)<1$ for some $N \geqq 1$. Then we get some $\varepsilon>0$ and $a<1$ such that $\left\|f^{N}\right\| \leqq a^{N}$ for all $f$ satisfying $\|f\| \leqq 1$ and $r(f) \leqq \varepsilon$.

Let then $\|f\| \leqq 1$ while $r(f) \leqq q<1$. Let $s$ be the positive integer satisfying $q^{s}<\varepsilon \leqq q^{s-1}$. It follows that $\left\|f^{N s}\right\| a^{N}$ and hence $\left\|f^{k N s}\right\| \leqq a^{k N}$ for all $k \geqq 1$. Using this fact we see that if $R=$ $\sum f^{j}: j \geqq s N$, then $\|R\| \leqq s N a^{N}\left(1-a^{N}\right)^{-1}$.

We have $(e-f)^{-1}=e+f+\cdots+f^{\lambda^{2}-1}+R$. Since $\|f\| \leqq 1$ we get $\left\|(e-f)^{-1}\right\| \leqq s N+\|R\| \leqq K_{0} s$. Finally $\varepsilon \leqq q^{s-1}$ which implies that $s \leqq K_{1}(1-q)^{-1}$. Hence (c) follows with $K_{q}=K_{0} K_{1}$.

Now we assume that (b) holds in $B$. Suppose that $r_{N}(B)=1$ for all $N$. To each $j \geqq 1$ we can choose $f_{j}$ such that $\left\|f_{j}\right\|=1$ and $r\left(f_{j}\right)<(j+1)^{-1}$, while $\left\|f_{j}^{j}\right\|^{1 / j}>1-1 / j$.

Let us consider $F=\left(f_{j}\right)$ in $B_{\infty}$. Since $\lim _{j \rightarrow \infty}\left\|F^{j}\right\|^{1 / j}=1$, it 
follows that there is some $w \in C^{1}$ satisfying $|w|=1$ while $w e-F$ is not invertible in $B_{\infty}$.

Consider the elements $g_{j}=\left(e-f_{j} / w\right)^{-1}$ which exist for all $j \geqq 1$. Clearly (b) implies that $\left\|g_{j}\right\| \leqq K$ for some fixed constant $K$. Since $\lim _{j \rightarrow \infty} r\left(f_{j}\right)=0$ it follows that the element $G=\left(g_{j}\right)$ exists in $B_{\infty}$. Now $(w e-F) G w^{-1}=e$ in $B_{\infty}$ which shows that $w e-F$ is invertible, a contradiction. Hence $r_{N}(B)<1$ must hold for some $N$.

Let us observe that a spectral null sequence $F=\left(f_{j}\right)$ simply is an element of $B_{\infty}$ for which $\|F\| \leqq 1$ and $\hat{F}\left(m_{\infty}\right)=0$. The following result is a direct consequence of Proposition 2.6.

THEOREM 3.2. The following two conditions on $B$ are equivalent:

(a) $\lim r_{N}(B)=0$ as $N \rightarrow \infty$.

(b) $M_{\infty}=\left\{m_{\infty}\right\}$.

Finally we study spectral null sequences satisfying polynomial conditions.

THEOREM 3.3. Let $p$ be a polynomial of the form $z^{s}\left(1+a_{1} z+\right.$ $\left.\cdots+a_{t} z^{t}\right)$, with $s>1$. Then there exist constants $K$ and $c$ with the following property: If $f \in B$ satisfies $\|f\| \leqq 1,\|p(f)\| \leqq \varepsilon$ and $r(f) \leqq \varepsilon$, where $\varepsilon \leqq c$, then $\left\|f^{s}\right\| \leqq K \varepsilon$.

Proof. For each $\varepsilon>0$ we put $S(\varepsilon)=\{f \in B:\|f\| \leqq 1,\|p(f)\| \leqq$ $\varepsilon$ and $r(f) \leqq \varepsilon\}$. Suppose the constants $c$ and $K$ do not exist. Then there is a decreasing sequence $\left(\varepsilon_{j}\right)$, with $\lim _{j \rightarrow \infty} \varepsilon_{j}=0$, while $S\left(\varepsilon_{j}\right)$ contains an element $f_{j}$ for which $\left\|f_{j}^{s}\right\|>j \varepsilon_{j}$.

We may assume that $1>\left|a_{1}\right| \varepsilon_{1}+\cdots+\left|a_{t}\right| \varepsilon_{1}^{t}$ holds. This implies that the elements $u_{j}=\mathrm{e}+a_{1} f_{j}+\cdots+a_{t} f_{j}^{t}$ are invertible in $B$.

Now $p\left(f_{j}\right)=f_{j}^{s} u_{j}$ and hence $j \varepsilon_{j}<\left\|f_{j}^{s}\right\| \leqq\left\|p\left(f_{j}\right)\right\|\left\|u_{j}^{-1}\right\| \leqq$ $\varepsilon_{j}\left\|u_{j}^{-1}\right\|$. This means that $\left\|u_{j}^{-1}\right\|>j$ for all $j$, so the element $G=$ $\left(u_{j}\right)$ is not invertible in $B_{\infty}$.

Now we obtain a contradiction by proving that $G$ must be invertible in $B_{\infty}$. Since $\lim _{j \rightarrow \infty}\left\|p\left(f_{j}\right)\right\|=0$ it follows that $\lim \left\|p\left(\pi_{N}(G)\right)\right\|=0$ as $N \rightarrow \infty$. Then Proposition 2.6. shows that $p(G)$ must vanish on $M_{\infty}$.

Hence the set $\hat{G}\left(M_{\infty}\right)$ is contained in the finite set of zeros of $p$. Using Theorem 2.4. we see that $\hat{G}\left(M_{\infty}\right)$ is connected. It follows that $\hat{G}\left(M_{\infty}\right)=\left\{\hat{G}\left(m_{\infty}\right)\right\}$. Clearly $\hat{G}\left(m_{\infty}\right)=1$ holds and hence $\hat{G}$ does not vanish on $M_{\infty}$. The choice of $\varepsilon_{1}$ shows that $\hat{G} \neq 0$ on $\Delta$ too. This proves that $G$ is invertible in $B_{\infty}$ which gives the desired contradiction.

Finally we raise some problems. We do not know if the condition that $r_{N}(B)<1$ for some $N>2$ implies that $r_{2}(B)<1$. We 
also ask if the condition that $r_{N}(B)<1$ for some $N \geqq 2$ implies that $\lim r_{J}(B)=0$ as $J \rightarrow \infty$.

\section{REFERENCES}

1. A. Bernard, Une caracterisation de $C(X)$ parmi les algebres de Banach, C. R. Acad. Sci. Paris, Ser. A 267, (1968), 63-63.

2. C. Graham, On a Banach algebra of Varapoulos, Functional Analysis, 3 (1969), 317-327.

Received April 1, 1970 and in revised form August 11, 1970.

Institut Mittag LefFleR 


\title{
PACIFIC JOURNAL OF MATHEMATICS
}

\section{EDITORS}

\author{
H. SAMELSON \\ Stanford University \\ Stanford, California 94305 \\ C. R. HobBY \\ University of Washington \\ Seattle, Washington 98105
}

J. DugundJI

Department of Mathematics

University of Southern California

Los Angeles, California 90007

RICHARD ARENS

University of California

Los Angeles, California 90024

\section{ASSOCIATE EDITORS}
E. F. BECKENBACH
B. H. NeumanN
F. WOLF
K. YOSHIDA

\section{SUPPORTING INSTITUTIONS}

\author{
UNIVERSITY OF BRITISH COLUMBIA \\ CALIFORNIA INSTITUTE OF TECHNOLOGY \\ UNIVERSITY OF CALIFORNIA \\ MONTANA STATE UNIVERSITY \\ UNIVERSITY OF NEVADA \\ NEW MEXICO STATE UNIVERSITY \\ OREGON STATE UNIVERSITY \\ UNIVERSITY OF OREGON \\ OSAKA UNIVERSITY
}

\author{
UNIVERSITY OF SOUTHERN CALIFORNIA \\ STANFORD UNIVERSITY \\ UNIVERSITY OF TOKYO \\ UNIVERSITY OF UTAH \\ WASHINGTON STATE UNIVERSITY \\ UNIVERSITY OF WASHINGTON
AMERICAN MATHEMATICAL SOCIETY
NAVAL WEAPONS CENTER

The Supporting Institutions listed above contribute to the cost of publication of this Journal, but they are not owners or publishers and have no responsibility for its content or policies.

Mathematical papers intended for publication in the Pacific Journal of Mathematics should be in typed form or offset-reproduced, (not dittoed), double spaced with large margins. Underline Greek letters in red, German in green, and script in blue. The first paragraph or two must be capable of being used separately as a synopsis of the entire paper. The editorial "we" must not be used in the synopsis, and items of the bibliography should not be cited there unless absolutely necessary, in which case they must be identified by author and Journal, rather than by item number. Manuscripts, in duplicate if possible, may be sent to any one of the four editors. Please classify according to the scheme of Math. Rev. Index to Vol. 39. All other communications to the editors should be addressed to the managing editor, Richard Arens, University of California, Los Angeles, California, 90024.

50 reprints are provided free for each article; additional copies may be obtained at cost in multiples of 50 .

The Pacific Journal of Mathematics is published monthly. Effective with Volume 16 the price per volume (3 numbers) is $\$ 8.00$; single issues, $\$ 3.00$. Special price for current issues to individual faculty members of supporting institutions and to individual members of the American Mathematical Society: $\$ 4.00$ per volume; single issues $\$ 1.50$. Back numbers are available.

Subscriptions, orders for back numbers, and changes of address should be sent to Pacific Journal of Mathematics, 103 Highland Boulevard, Berkeley, California, 94708.

\section{PUBLISHED BY PACIFIC JOURNAL OF MATHEMATICS, A NON-PROFIT CORPORATION}

Printed at Kokusai Bunken Insatsusha (International Academic Printing Co., Ltd.), 270, 3chome Totsuka-cho, Shinjuku-ku, Tokyo 160, Japan. 


\section{Pacific Journal of Mathematics}

\section{Vol. 40, No. $2 \quad$ October, 1972}

Louis I. Alpert and L. V. Toralballa, An elementary definition of surface area in $E^{n+1}$ for smooth surfaces...........................

Eamon Boyd Barrett, A three point condition for surfaces of constant mean curvature........................................

Jan-Erik Björk, On the spectral radius formula in Banach algebras ....... 279

Peter Botta, Matrix inequalities and kernels of linear transformations . . . . 285

Bennett Eisenberg, Baxter's theorem and Varberg's conjecture ........... 291

Heinrich W. Guggenheimer, Approximation of curves .............. 301

A. Hedayat, An algebraic property of the totally symmetric loops associated with Kirkman-Steiner triple systems ....................... 305

Richard Howard Herman and Michael Charles Reed, Covariant representations of infinite tensor product algebras ................

Domingo Antonio Herrero, Analytic continuation of inner

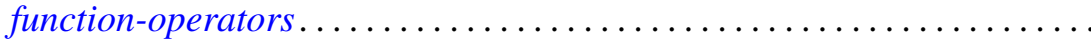

Franklin Lowenthal, Uniform finite generation of the affine group......... 341

Stephen H. McCleary, 0-primitive ordered permutation groups .......... 349

Malcolm Jay Sherman, Disjoint maximal invariant subspaces .......... 373

Mitsuru Nakai, Radon-Nikodým densities and Jacobians .............. 375

Mitsuru Nakai, Royden algebras and quasi-isometries of Riemannian manifolds. . .

Russell Daniel Rupp, Jr., A new type of variational theory sufficiency

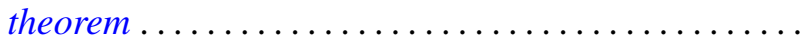

Helga Schirmer, Fixed point and coincidence sets of biconnected multifunctions on trees..........................

Murray Silver, On extremal figures admissible relative to rectangular

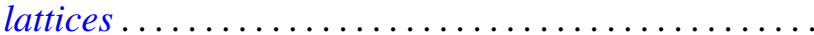

James DeWitt Stein, The open mapping theorem for spaces with unique segments ...

Arne Stray, Approximation and interpolation

Donald Curtis Taylor, A general Phillips theorem for $C^{*}$-algebras and some applications

Florian Vasilescu, On the operator $M(Y)=T Y S^{-1}$ in locally convex algebras...

Philip William Walker, Asymptotics for a class of weighted eigenvalue problems...

Kenneth S. Williams, Exponential sums over $\mathrm{GF}\left(2^{n}\right)$. 